\title{
专访中国石墨烯领军人物：刘忠范院士及他的团队
}

《物理化学学报》编辑部

北京大学化学与分子工程学院, 北京 100871

\section{Interview with the Pioneers of Graphene Research in China: Academician Zhongfan Liu and His Research Team}

\author{
Editorial Office of Acta Physico-Chimica Sinica \\ College of Chemistry and Molecular Engineering, Peking University, Beijing 100871, P. R. China. \\ Email:whxb@pku.edu.cn. \\ Published online: April 9, 2019.
}

英国曼彻斯特大学物理学家安德烈·海姆和康斯坦丁·诺沃肖洛夫于 2004 年成功地从石墨中剥离出石墨 烯, 并表征了它的性质, 两人也因 “在二维石墨烯材料的开创性实验”, 共同获得 2010 年诺贝尔物理学奖。

石墨烯，因其拥有独特的物理性能而被广泛关注。它是目前世界上已知最薄、最坚硬、导电性和导热 性最好的材料, “多才多艺”的性质使得石墨烯有着广阔的应用前景, 可以运用在计算机芯片上, 大幅度提 高计算速度。用石墨烯作为导电添加剂, 可以显著提高锂电池的充电速度和综合性能。所以人们称它为会 改变世界的材料。

我们有幸采访了石墨烯领域的领军人物, 同时也是《物理化学学报》的主编——刘忠范院士，为我们 分享他的研究经历及对国内外石墨烯行业的分析。

问题1: 刘院士，作为享誉世界的石墨烯领域的领 军人物, 您是否还记得您是何时因何种契机对石 墨烯这个新兴的领域产生浓厚兴趣的?

回答: 我原来是做碳纳米管的, 碳纳米管和石墨烯 是姊妹关系, 因为把单层石墨片卷起来就变成了 碳纳米管。当时经常这样介绍碳纳米管, 现在看来 不卷起来更重要。2004年10月22日第一篇石墨烯 文章问世, 两位主要作者在 6 年后斩获诺贝尔奖, 继而掀起了延续至今的石墨烯热。我实际上是 2008年开始进入石墨烯领域的。从碳纳米管到石 墨烯, 正好经历了十年的时间。我为什么会选择做 石墨烯呢? 因为石墨烯和碳纳米管从制备方法、表 征技术到物理性质都非常类似, 所以很多碳纳米 管玩家都闯入了石墨烯领域。我从2004年到2008 年一直在观望石墨烯, 2008年花了大半年时间满 世界参加相关学术会议做深入调研, 最后才下定 决心的。现在看来这个决策非常正确, 因为从产业 化的角度来看, 石墨烯比碳纳米管靠谱得多。
问题2: 在科研的道路上有哪些重要的人影响了您?

回答: 我曾经写过一篇回忆文章, 标题是《兴趣、 机遇与选择》, 回顾了我三十岁以前的一些经历, 其 中提到了几位对我影响非常大的老师。我初中和 高中的化学老师都教得特别好, 所以我喜欢化学, 在高考时毫不犹豫地报考了化工专业。到了大学 之后, 物理化学课的老师讲得非常好, 于是我后来 选择了物理化学专业继续深造。大学毕业之后赴 日本留学, 从横滨国立大学到东京大学, 遇到了恩 师藤岛昭先生。也正是藤岛昭先生把我真正领进 了科学的殿堂, 让我领略了科学的鬼米力。在藤岛昭 先生的实验室学习了五年之后, 带着对新知识的 渴求, 我选择到有过一面之缘的有机半导体研究 先驱井口洋夫先生那里做博士后, 我后来从事交 叉学科研究也与这位老先生密切相关。井口洋夫 先生让我对科学的认识又提升了一个层次。我到北 京大学工作也与一位老先生有关, 他就是蔡生民 先生, 现在我们见面他还会亲切地喊我“小刘”。他 
当年极力动员我到北京大学工作, 可以说对我的 人生规划产生了深远的影响。我回国之后, 得到了 蔡生民先生的方方面面的支持。所以在人生道路 上遇到的多位良师是我的运气, 他们对我的学业 和人生都产生了至关重要的影响。

问题3: 您研究石墨烯已经超过 10 年了, 您认为石 墨烯领域有哪些最重要的发现?

回答: 石墨烯属于二维材料, 早年二维材料并没有 得到人们的重视, 因为按照朗道(L.D. Landau)和佩 尔斯(R.E. Peierls)的理论, 二维材料是不能稳定存 在的。2004年安德烈.海姆和康斯坦丁. 诺沃肖洛夫 的文章的真正价值并不在于发现了石墨烯, 而是第 一次实验测量了二维材料石墨烯的性质。本来被 认为不应该存在的东西, 不但被做出来了, 而且还 发现它的性质非常“好玩”。当然, 现在人们认为, 理论并没有错, 这种现实存在的二维材料并非真 正的理想平面结构, 而是存在着波纹状结构。这个 波纹非常非常的小, 只有埃量级, 所以很难测量出 来。当把石墨烯这样的二维材料放到支撑衬底上 时, 这种波纹结构就会消失了。就像高山上下了一 层雪, 它不是雪的形状, 是山的形状。

石墨烯领域重要的发现非常多。石墨烯材料 的导电性比银还好, 导热性也是目前最好的。早期 的石墨烯研究就展示了诸多新奇的性质, 如最小 量子电导率、半整数量子霍尔效应、反常量子霍尔 效应、室温量子霍尔效应、分数量子霍尔效应、Klein 隧穿、噟磁场等。最新的研究发现, 双层石墨烯存 在着“魔角”, 当转角为 $1.1^{\circ}$ 左右时, 出现超导现象。 尽管炒的有点过头, 但也的确说明石墨烯仍然是 有继续开垦价值的富矿。

问题4: 您能否列举一些您的课题组正在进行的最 重要的几个项目?

回答: 我的团队从事了 10 年的石墨烯研究, 在石墨 烯材料制备和杀手锏级应用探索方面取得了一系 列创新性成果, 正是这些突破催生了北京石墨烯 研究院。我比较得意的代表性工作有以下几个。首 先是我们发明的超洁净石墨烯制备技术。高温炉 子里生长出来的石墨烯薄膜其实很脏, 通常大家 都认为是剥离过程中带来的污染物。我们的研究 发现, 这些脏东西是生长过程中的本征污染物, 与 生俱来的东西。为此, 我们发明了没有本征污染的 超洁净石墨烯薄膜生长方法, 这种干净的石墨烯 在剥离后也是干净的。超洁净石墨烯显示出接近
理论极限的优良特性, 代表着石墨烯材料生长的 发展前沿。

第二个是超级石墨烯玻璃, 我们通过长达五 年的艰苦努力, 实现了在普通玻璃上的石墨烯生 长。目前全世界只有我们能够做出来, 属于重大技 术突破。石墨烯通常是在金属催化剂表面生长出 来的, 金属催化剂起着催化裂解碳源分子和降低 石墨化温度的作用。我们最早尝试在普通玻璃上 生长石墨烯。因为没有高效的催化剂存在, 难度可 想而知。经过不解的努力和坚持, 我们找到了诀 倥, 发明了一系列生长技术, 实现了在任意玻璃上 的高质量石墨烯生长。这种超级石墨烯玻璃, 既拥 有非常好的导电性, 又拥有极好的导热性, 同时保 持了足够的透光度, 表面化学特性也发生了根本 性变化, 完全不同于传统的玻璃。超级石墨烯玻璃 拥有广阔的应用前景, 手机触摸屏、透明暖气片、 智能窗、投影屏、高效细胞培养血、光学传感器, 等等。

我们的得意之作还有烯碳光纤, 这是一个全 新的研究领域。我们在石英光纤表面直接生长高 质量的石墨烯薄膜, 已经实现了批量制备。这种新 一代的烯碳光纤可用于制备电光调制器、超快激 光器、光纤传感器以及特种防腐光纤。我们之所以 有此突破, 得益于超级石墨烯玻璃的前期工作基 础。这也是我的突发奇想, 因为光纤是石英玻璃纤 维, 石墨烯在玻璃上可以生长, 自然在光纤上应该 也可以。

石墨烯原材料制备是我们的强项，也是未来 石墨烯产业的基石。我们目前已经实现了四英寸 无褶皱单晶石墨烯晶圆的批量制备, 年产量能达 到一万片; 多晶石墨烯薄膜年产量达到两万平方 米; 石墨烯玻璃年产量达到五千平方米; 石墨烯玻 璃纤维布也实现批量生产。我们不仅制备高端石 墨烯材料, 还制造石墨烯装备, 并将很快投放市场。

问题5: 您研究石墨烯以来, 您的研究侧重点是否 发生了改变?

回答: 在逾十年的石墨烯研究中, 前五年石墨烯产 业化的前景还不明朗, 所以我主要从事基础研究, 发展高品质石墨烯材料的生长方法和化学修饰方 法, 探索石墨烯材料的应用领域, 自然也是追求发 文章, 发所谓的高档次文章。从2013年左右开始, 我的侧重点发生了重大变化。尽管发了很多不错 的文章, 在国际上也已经小有名气, 但缺少真正的 成就感。这时我面临着一个新的抉择, 是像很多石 墨烯玩家一样, 寻找新的文章富矿, 进入其他二维 
材料领域, 还是继续做石墨烯研究。经短暂的思 考, 我下定决心在石墨烯材料的产业化推进方面 做点事情, 从此开始了一个充满挑战和荆棘的新 征程。五年多的实践表明, 与做真正有实用价值的 产业化技术研发相比, 发文章实在是太容易了, 因 为后者不必关心有用没用, 好玩就行。一旦考虑到 实用性, 就会发现很多发文章的“套路”都行不通 了。我经常跟学生讲, 如果只是为了发文章, 我可 以有一百个主意, 发一百篇文章, 但是当考虑产业 化前景时, 就只剩下十个主意了, 难度大幅度提 升, 因为你不能玩花样了。即便是十个主意, 到最 后可能只有一两个是行得通的, 甚至一个不通, 这 才是真正的挑战性工作。我的体会是, 要做点真正 有用的东西, 或者上货架, 或者上书架, 不能把你 的精力和才华浪费到玩花样上。真正对科学有用 的东西, 不是说发几篇好文章, 而是能够留到科学 史上, 写到教科书里。而真正对产业有用的东西, 那是实实在在的实用性技术, 需要经过千锤百炼, 浴火重生。所以从这个角度讲, “顶天”也难, “立 地” 更难。但是我们目前的评价机制, 是鼓励大家 只做对自己有用的东西, 发一大堆所谓的高档次 文章, 拿一大堆头衔, 换来更好的待遇而已。从 2008年至今已经整整十年, 我的团队完成了从实 验室到北京石墨烯研究院的跨越。下一个十年将 会如何, 我充满期待。有一点非常清楚, 绝非几篇 文章的产出, 而必将是一个新的飞跃。

问题 6: 目前中国石墨烯的研究是否走在了国际 前列?

回答: 我经常被问到这个问题, 北京石墨烯研究院 的石墨烯研究肯定已经走在了世界的前列。中国石 墨烯研究的整体水平是否已经走在了前列应该从 两个方面来看。一方面是统计数据, 从2011年起, 中国的石墨烯文章数量已经位居世界第一, 接近 六万篇, 远远超过第二名美国的两万多篇; 中国申 请的石墨烯专利占了全球的 $54 \%$ 以上, 也是遥遥领 先。目前中国涉及石墨烯业务的公司已经超过五 千家, 并且呈现迅速增加之势。因此, 从统计学意 义上讲, 中国的石墨烯研究已经领先世界, 拥有绝 对的“数量”优势。但是, 数字后面也隐藏着巨大的 危机。我正在组织一个正式的调研活动, 进行全国 性的实地调查, 了解中国石墨烯产业的发展现状, 为国家制定相关政策提供决策依据。我们已经在 北京和江苏走访了多家石墨烯企业, 应该说不容 乐观, 挣扎在生死线上的企业绝非少数。另一方 面, 我在各种场合也一直在讲, 中国的石墨烯研究
跟国外不在一个频道上。我们更关注马上能赚到 钱的东西, 我们有七百多家石墨烯涂料企业, 还有 众多的石墨烯电热器和所谓的大健康企业、以及 更多的石墨烯电池玩家，石墨烯内衣、石墨烯袜 子、石墨烯护腰、石墨烯口罩, 甚至还有石墨烯首 饰, 应有尽有。反观国外, 他们更多关注的是未来, 是高大上的石墨烯产品开发, 如柔性石墨烯逻辑 电路、石墨烯微波通讯器件、石墨烯太赫兹传感 器、石墨烯传感器和光探测器、石墨烯汽车、石墨 烯海水淡化技术等。显而易见, 这些东西不可能立 即变现, 不能期待几年之内就有多么大的产业, 但 是它们代表着石墨烯材料的未来。我特别担心的 是, 我们起了个大早, 赶了个晚集。因为我们只关 注现在, 根本没有考虑未来。

问题7: 目前石墨烯领域的发展存在的最大的挑战 有哪些?

回答: 有两个挑战, 首先是制备问题, 制备决定未 来。未来的石墨烯产业依赖于石墨烯材料本身, 没 有好的材料也就失去了产业的根基, 所以把材料 做好是关键。石墨烯制备看似简单, 实际上想要做 好不容易, 虽然我做了十年石墨烯薄膜生长, 感觉 是越做越难。这点与碳纤维材料非常相似。碳纤维 已有将近六十年的历史, 质量也是一个逐渐提升 的过程。早年的碳纤维只能用做钓鱼竿和高尔夫 球杆。而现在的碳纤维复合材料是航空航天和国 防军工领域的杀手锏级材料, 波音787就大量使用 了这种新型复合材料。目前的石墨烯材料质量还 差得远，在制备技术上还有非常大的提升空间。还 要考虑价格问题, 好的材料自然比较贵, 太贵了市 场无法接受。尽管我不赞成“物美价廉”的口号, 但 是太贵的话很难被市场所接受, 相信未来可以通 过规模化的生产同时解决质量和价格问题。

第二个挑战是应用问题。理论上石墨烯有着 广阔的应用前景, 但现实是更多地作为“工业味 精” 使用, 似乎放在哪里都挺好, 既虚实难辨, 也 不是不可替代。人们需要找到石墨烯材料的“杀手 锏”级用途, 非它莫属, 缺它不行。理性地讲, 这 条路还很漫长。

问题8: 您认为石墨烯材料发展和应用对普通人的 生活会有哪些影响?

回答: 我给石墨烯材料勾画了三种前途。第一种前 途类似于碳纤维材料, 在某些领域找到不可或缺 的用途, 成为杀手锏级的应用。第二种前途类似于 塑料, 一百年前人们发明了塑料, 极大地便利了人 
类生活, 已经渗透在日常生活的方方面面。石墨烯 材料也有这种潜质, 因为理论上有太多的可能, 在 未来也可能像塑料一样进入我们的日常生活。第 三种前途类似于硅材料。没有硅材料, 就没有集成 电路, 自然也就无法进入信息化时代。甚至可以 讲, 我们现在生活在“硅时代”。石墨烯材料拥有远 优于硅材料的电子学特性, 可用来制造未来的超 快集成电路。在未来的某一天, 石墨烯材料有可能 替代硅材料, 制造“碳基集成电路”, 从而把人类带 入“碳时代”。当然, 这还是一个美好的梦想, 需要 解决诸多技术问题。

问题9: 作为国内石墨烯行业顶尖研究院的创办 者, 您对国内同样开展石墨烯研究的课题组, 有什 么好的建议吗?

回答: 第一是不要太着急, 不能过于急功近利。应 弘扬工匠精神, 把一件事情做到极致。因为真正的 核心技术, 是“鳌”出来的, 需要耐心。我研究石墨 烯十年了, 尤其在石墨烯薄膜制备方面下了极大 的功夫, 但是也不敢说解决了所有问题。第二是不 要一哄而上, 做低水平的重复性工作, 进行恶性竞 争, 这是没有前途的。第三是从基础研究抓起, 深 入挖掘石墨烯这个富矿, 找到新的性质和新的用 途, 前面提到的双层石墨烯的超导效应就是一个 典型的例子。

问题 10: 随着期刊竞争的日益激烈, 尤其是在英文 期刊一统科技界的形势下, 很多中文期刊都转为 英文, 您作为中文期刊的主编, 您认为中文期刊存 在的价值和意义在哪里? 对中文期刊的发展有什 么建议?

回答: 中文期刊的角色定位与英文期刊完全不同, 我与《科学通报》主编高福院士在这方面有着高度 共识, 绝不能简单地拿所谓的影响因子高低说事 儿, 影响因子不是衡量中文期刊水平的唯一标准。 中文期刊是一个向国人传播本领域最新最前沿研
究进展的学术平台, 这是英文期刊所不具备的。冊 庸置疑, 不是所有的国人都是英语达人, 也不是所 有的人都愿意看英文期刊, 我们的企业研发人员 或许更重视中文期刊。另外, 从文化传承层面上 讲, 中国人应有用母语写的学术期刊。我对中文期 刊的建议是, 高度重视文章的学术质量, 及时、准 确地向国人传播最前沿的科技进展, 这是中文期 刊的使命所在。

问题11：您从教多年培养了大批优秀的青年科学 家, 有一些已经成为业内的领军人物。您在培养学 生方面有哪些经验可以与大家分享? 您对青年科 学家的期望是什么?

回答: 回国26年, 我最大的骄傲是培养的教授/研 究员已经超过 50 个, 还有众多的副教授。我的目标 是在有生之年, 至少培养 100 个教授。我愿意去发 现人才、培养人才，在这方面深受我导师的影响。 我经常提醒自己, 做导师不易, 会影响学生的一 生, 要以身作则, 不能大意。我的绝大多数学生在 毕业之后还在从事科研工作，说明并没有讨厌科 研这条路。作为导师要重视言传身教, 身教胜于言 传。如果你自己不喜欢科研这条路, 难以想象你会 说服学生喜欢。学生是导师的“作品”, 而不是廉价 劳动力。带学生也是一门艺术, 要给他们足够的空 间, 去发挥, 去发展, 去展示自己的才华。我还有 一个目标, 要培养十个亿万富翁, 让学生们真正体 会到, 知识就是财富。我在全力以赴地推进北京石 墨烯研究院工作, 这是一个很好的平台, 也是一个 很好的实现第二个目标的抓手，我充满期待。

我希望青年科学家要沉下心来, 做点真正有 价值的东西, 要么上货架, 要么上书架。我非常理 解青年科学家们背负的各种压力, 但是不必操之 过急, 因为做学问是一辈子的事情, 不必只争朝 夕。找到一个自己喜欢的方向, 坚持做下去, 你一 定会有所成就, 一定会被大家所认可。

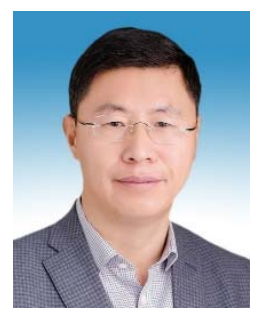

刘忠范, 北京大学博雅讲席教授, 中国科学院院士, 发展中国家科学院院士, 中组 部首批万人计划杰出人才, 教育部首批长江学者特聘教授, 首批国家杰出青年科学基金 获得者。英国物理学会会士, 英国皇家化学会会士, 中国微米纳米技术学会会士。1983 年毕业于长春工业大学，1984年留学日本，1990年获东京大学博士，1990-1993年东京 大学和国立分子科学研究所博士后。1993年6月回北京大学任教, 同年晋升教授。

现任北京石墨烯研究院院长、北京大学纳米科学与技术研究中心主任。中国化学会 副理事长、中国国际科技促进会副会长、中关村石墨烯产业联盟理事长、中关村科技园 区丰台园科协第三届委员会主席、教育部科技委委员及学风建设委员会副主任和国际合作学部副主任。 
曾任北京大学现代物理化学研究中心主任(1995-2002), 物理化学研究所所长(2006-2014), 北京市科委 挂职副主任(2016-2017), 北京市低维碳材料工程中心主任(2013-2018), 国家攀登计划(B)、973计划和纳 米重大研究计划项目首席科学家, 国家自然科学基金 “表界面纳米工程学” 创新研究群体学术带头人(三 期)等。

主要从事纳米碳材料、二维原子晶体材料和纳米化学研究, 在石墨烯、碳纳米管的化学气相沉积生 长方法及其应用领域做出了一系列开拓性和引领性工作, 是国际上具有代表性的纳米碳材料研究团队之 一。发表学术论文 560 余篇, 申请中国发明专利 100 余项。近年来致力于推进石墨烯的产业化核心技术研 发工作并不断取得重要突破, 发明了超级石墨烯玻璃、超洁净石墨烯、烯碳光纤、石墨烯玻璃纤维、石 墨烯光化学能带工程等一系列新概念和新技术, 推动了石墨烯领域的快速发展。在早期工作中, 还建立 了基于扫描探针显微技术的针尖化学研究方法和超高密度光电化学信息存储方法, 率先将有机小分子自 组装技术引入准一维碳纳米管研究领域, 建立了单壁碳纳米管的有序自组装方法等。

获日中科技交流协会 “有山兼孝纪念研究奖” (1992)、香港求是科技基金会杰出青年学者奖(1997)、 中国分析测试协会科学技术奖一等奖(2005)、教育部高等学校科学技术奖自然科学一等奖(2007)、国家 自然科学二等奖(2008, 2017)、中国化学会-阿克苏诺贝尔化学奖(2012)、宝钢优秀教师特等奖(2012)、日 本化学会胶体与界面化学年会Lectureship Award (2016)、北京大学方正教师特别奖(2016)、“北京市优秀教 师” (2017)、ACS Nano Lectureship Award (2018)等。

现任《物理化学学报》主编、《科学通报》副主编, Adv. Mater、ACS Nano、Small、Nano Res. 、ChemNanoMat、 APL Mater、National Science Review等国际期刊编委或顾问编委。

第十二届全国人大代表, 第十三届全国政协常委, 北京市政协副主席。九三学社第十四届中央委员 会副主席, 九三学社北京市第十三届委员会主任委员。 